\title{
Genome
}

\section{Abscisic acid and ethylene biosynthesis-related genes are associated with anthocyanin accumulation in purple ornamental cabbage, Brassica oleracea var. acephala}

\begin{tabular}{|c|c|}
\hline Journal: & Genome \\
\hline Manuscript ID & gen-2019-0038.R1 \\
\hline Manuscript Type: & Article \\
\hline $\begin{array}{r}\text { Date Submitted by the } \\
\text { Author: }\end{array}$ & 16-May-2019 \\
\hline Complete List of Authors: & $\begin{array}{l}\text { Jin, Si-Won ; Sunchon National University, Department of Horticulture } \\
\text { Rahim, Md Abdur; Sunchon National University, Department of } \\
\text { Horticulture } \\
\text { Jung, Hee-Jeong; Sunchun National University, Department of } \\
\text { Horticulture } \\
\text { Afrin, Khandker Shazia; Sunchon National University, Department of } \\
\text { Horticulture } \\
\text { Kim, Hoy-Taek ; Sunchon National University, Department of } \\
\text { Horticulture } \\
\text { Park, Jong-In; Sunchon National University, Department of Horticulture } \\
\text { Kang, Jong-Goo; Sunchon National University, Department of } \\
\text { Horticulture } \\
\text { Nou, Ill Sup; Sunchon National University, Department of Horticulture }\end{array}$ \\
\hline Keyword: & abscisic acid, ethylene, anthocyanin, ornamental cabbage \\
\hline $\begin{array}{r}\text { Is the invited manuscript for } \\
\text { consideration in a Special } \\
\text { Issue? : }\end{array}$ & Not applicable (regular submission) \\
\hline
\end{tabular}

\section{SCHOLARONE ${ }^{m}$} Manuscripts 
1 Abscisic acid and ethylene biosynthesis-related genes are associated with anthocyanin 2 accumulation in purple ornamental cabbage, Brassica oleracea var. acephala 3

4 Si-Won Jin, Md Abdur Rahim, Hee-Jeong Jung, Khandker Shazia Afrin, Hoy-Taek Kim, 5 Jong-In Park, Jong-Goo Kang and Ill-Sup Nou*

6

7 Department of Horticulture, Sunchon National University, Suncheon 57922, Republic of 8 Korea

9

10 *Correspondence: nis@sunchon.ac.kr (I.S.N), Tel.: +82-61-750-3249. 
12 Abstract: Purple ornamental cabbage (Brassica oleracea var. acephala) is a popular decorative plant, cultivated for its colorful leaf rosettes that persist in cool weather. It is characterized by green outer leaves and purple inner leaves, whose purple pigmentation is due to the accumulation of anthocyanin pigments. Phytohormones play important roles in anthocyanin biosynthesis in other species. Here, we identified 14 and 19 candidate genes putatively involved in abscisic acid (ABA) and ethylene (ET) biosynthesis, respectively, in $B$. oleracea. We determined the expression patterns of these candidate genes by reversetranscription quantitative PCR (RT-qPCR). Among candidate ABA-biosynthesis-related genes, the expressions of BoNCED2.1, BoNCED2.2, BoNCED6, BoNCED9.1 and BoAAO3.2 were significantly higher in purple compared to green leaves. Likewise, most of the ET biosynthetic genes (BoACS6, BoACS9.1, BoACS11, BoACO1.1, BoACO1.2, BoACO3.1, BoACO4 and $B o A C O 5$ ) had significantly higher expression in purple compared to green leaves. Among these genes, BoNCED2.1, BoNCED2.2, BoACS11 and BoACO4 showed particularly strong associations with total anthocyanin content of the purple inner leaves. Our results suggest that $\mathrm{ABA}$ and $\mathrm{ET}$ might promote the intense purple pigmentation of the inner leaves of purple ornamental cabbage.

Key words: abscisic acid, ethylene, anthocyanin, ornamental cabbage. 


\section{Introduction}

Ornamental cabbage (Brassica oleracea var. acephala) is an attractive cool-weather decorative plant of the Brassicaceae family. A form of cabbage whose leaves do not develop into a typical head, it is more closely related to wild cabbage than to the domesticated types (Huaiming et al. 1995). Ornamental cabbage is widely used in potted plant or cut form due to its attractive foliage color and ability to grow at low temperatures during cool weather (Wang et al. 2011). In addition, its foliage has a long-lasting ornamental period (3-4 months) (Ren et al. 2015). It is also known as 'leaf peony', 'flowering kale' and 'ornamental kale', and shows a range of foliage colors including red, purple, lavender, white, blue and violet (Wei et al. 2008; Zhang et al. 2012; Ren et al. 2015). Purple ornamental cabbage is characterized by brilliant purple inner leaves surrounded by outer green leaves (Liu et al. 2017; Jin et al. 2018a). The purple pigmentation of the inner leaves is due to an accumulation of anthocyanins (Zhang et al. 2012; Jin et al. 2018b, 2018a). Ornamental cabbage is also edible, 2007). consumption (Bergfeldt 2013; Fetouh 2018).

Anthocyanins are plant-derived bioactive compounds belonging to the flavonoid class of secondary metabolites and are responsible for the red, purple and blue colors of reproductive, as well as vegetative, organs of plants (Middleton et al. 1993; Deluc et al. 2006; Rahim et al. 2014). The differences in colors produced by anthocyanins depends on the $\mathrm{pH}$ of the vacuole, co-pigments including flavonols and flavones, and metal ions, as well as cell shape (Mol et al. 1998). In addition to providing brilliant pigmentation, anthocyanins help plants in pollination and seed dispersal, and protect from biotic and abiotic stresses (Pourcel et al.

Anthocyanin biosynthesis and its transcriptional regulation have been well studied in many plant systems including the Brassicaceae species Arabidopsis thaliana and B. oleracea 
56 (Baudry et al. 2006; Yuan et al. 2009; Rahim et al. 2014, 2017, 2019; Jin et al. 2018b).

57 Expression of the anthocyanin biosynthetic genes is coordinately regulated by three

transcription factor (TFs) families through formation of a MYB-bHLH-WD40 transcriptional complex (Baudry et al. 2006; Allan et al. 2008). In addition to these three TF families, several other TFs were also recently reported to be associated with anthocyanin biosynthesis, including bZIP (HY5, ELONGATED HYPOCOTYL 5), MADS box and WRKY (Gyula et al. 2003; Jaakola 2013; Schluttenhofer and Yuan 2015).

Plants also accumulate anthocyanin pigments in different organs to cope with environmental stresses (Chalker-Scott 1999). Low temperature induces anthocyanin accumulation in maize seedlings, which also correlates with higher expression of the structural genes of the anthocyanin biosynthetic pathway (Christie et al. 1994). Recently, Zhang et al. (2018) reported that low temperature enhanced anthocyanin and proanthocyanidin biosynthesis to cope with oxidative damage in strawberry.

Plant hormones play an important role in anthocyanin biosynthesis (Das et al. 2012; An et al. 2018). For example, abscisic acid (ABA), ethylene (ET), cytokinins (CK), jasmonate (JA) and brassinosteroids (BR) enhance anthocyanin production by activating the structural genes of the anthocyanin biosynthetic pathway (Deikman and Hammer 1995; El-Kereamy et al. 2003; Loreti et al. 2008; Shan et al. 2009; Shen et al. 2014; An et al. 2018), whereas auxin (IAA) and gibberellins (GA) decrease anthocyanin production by suppressing these genes (Loreti et al. 2008; Ji et al. 2015). However, little is known about the role of ABA and ET in anthocyanin biosynthesis in brassica crops, including ornamental cabbage. The aim of this study was to identify genes related to ABA and ET biosynthesis and to determine their expression patterns in the inner purple and outer green leaves of ornamental cabbage.

\section{Materials and methods}




\section{Experimental plant materials}

The purple and green leaves of an ornamental cabbage line (SCNU-OC-41-102), previously reported as purple ornamental cabbage with purple inner leaves by our research group (Jin et al. 2018a), were used in this study (Fig. 1a). Seeds were obtained from Department of Horticulture, Sunchon National University, Republic of Korea, and sown in a nursery soil mixture in a plant growth chamber. After 28 days, the seedlings were moved to a glasshouse. Purple (inner, third leaf) and green (outer, $11^{\text {th }}$ leaf) leaves of a 67-day-old plants were sampled and immediately frozen in liquid nitrogen, and stored at $-80{ }^{\circ} \mathrm{C}$. genes using the maximum-likelihood method with 1000 bootstrap values by MEGA6.0 (Tamura et al. 2013). Since the ornamental cabbage (Brassica oleracea var. acephala) genome is not publicly available, the $B$. oleracea genome database 'Bolbase' (Yu et al. 2013) was used as a reference. Subsequently, the microsyntenic relationships of ABA and ET biosynthetic genes among $B$. oleracea, $B$. rapa and $A$. thaliana were identified using the al. 2009).

\section{Determination of total anthocyanin content}

Total anthocyanins were isolated from the purple (inner) and green (outer) leaves of ornamental cabbage with methanol containing $1 \% \mathrm{HCl}$ at room temperature. The leaves were 
ground in liquid nitrogen and transferred into the methanol/HCl solution. The mixtures were then homogenized and centrifuged at $14,000 \mathrm{rpm}$ for $14 \mathrm{~min}$. The absorbance of the supernatant was measured spectrophotometrically at wavelengths of $530 \mathrm{~nm}$ and $657 \mathrm{~nm}$. Anthocyanin content was presented as total anthocyanins $=\left(\mathrm{A}_{530}-0.25 \times \mathrm{A}_{657}\right) \times \mathrm{FW}^{-1}$, where $\mathrm{A}_{530}=$ absorbance at $530 \mathrm{~nm} ; \mathrm{A}_{657}=$ absorbance at $657 \mathrm{~nm}$; and $\mathrm{FW}=$ fresh weight of leaves (g) (Mehrtens 2005).

\section{Total RNA isolation and cDNA synthesis}

The leaf tissues were ground into a fine powder with a mortar and pestle in liquid nitrogen. $100 \mathrm{mg}$ of leaf tissue powder was used for isolation of RNA using a commercial kit

116 (RNeasy mini, Qiagen, USA) according to the manufacturer's instruction. RNA quantity and integrity were checked with a Nanodrop spectrophotometer (NanoDrop Technologies, Wilmington, Delaware, USA) and gel electrophoresis. A total of $1 \mu \mathrm{g}$ total RNA was used for cDNA synthesis using the SuperScript ${ }^{\circledR}$ III First-Strand Synthesis System (Invitrogen, Gaithersburg, MD).

\section{Gene expression analysis by RT-qPCR}

The expression profiling of selected genes was carried out using RT-qPCR with 'LightCycler 96' (Roche, Mannheim, Germany). The qRT-PCR reactions were performed using ' $2 x$ qPCRBIO SyGreen Blue Mix Lo-ROX’ (PCR Biosystems Ltd., London, UK) with genespecific primers (Table 1) and $45 \mathrm{ng} / \mu \mathrm{lDNA}$ as templates. The gene-specific primers were designed using the Bolbase (Yu et al. 2013) B. oleracea genomics database. The RT-qPCR reaction condition was an initial $95{ }^{\circ} \mathrm{C}$ for $5 \mathrm{~min}$ for enzymatic activation followed by 50 cycles of $95{ }^{\circ} \mathrm{C}$ for $10 \mathrm{~s}, 60{ }^{\circ} \mathrm{C}$ for $10 \mathrm{~s}$ and $72{ }^{\circ} \mathrm{C}$ for $15 \mathrm{~s}$. The gene expression profiling in this study was performed with three independent biological and three technical replicates. 
The $\mathrm{Cq}$ values obtained by qRT-PCR were analyzed with the LightCycler 96 program

132

\section{Statistical analysis}

Analysis of variance and tests for significance were performed using Minitab 17 (Minitab Inc., USA). The mean separation was accomplished with the Tukey's pairwise comparison.

\section{Results}

\section{High leaf anthocyanin content correlates with purple color}

We determined the anthocyanin levels in purple (inner) and green (outer) leaves of ornamental cabbage. The results confirmed that total anthocyanin content was significantly higher in purple leaves compared to green leaves of ornamental cabbage (Fig. 1b).

\section{Phylogenetic analysis reveals $14 \mathrm{ABA}$ and 19 ET biosynthetic gene candidates in}

\section{Brassica oleracea}

We performed an intensive phylogenetic analysis to identify candidate genes related to ABA and ET biosynthesis. We selected Arabidopsis ABA- and ET-biosynthesis-related genes according to Baron et al (2012), and Booker and DeLong (2015), respectively. To accomplish this, we performed BLAST analysis of the protein sequences of Arabidopsis thaliana retrieved from the Arabidopsis Information Resource (TAIR, https://www.arabidopsis.org/) against the $B$. oleracea and $B$. rapa genomes using the $B$. oleracea Genome Database 'Bolbase' v1.0 (Yu et al. 2013), the Plant Genomics Resource 'Phytozome' FPse v1.3 
156 (Goodstein et al. 2011) with default parameters, respectively. We aligned the protein

157

158

159

160

161

162

163

164

sequences with MUSCLE program and visualized them in a phylogenetic tree using the maximum-likelihood method with 1000 bootstrap values by MEGA6.0 (Tamura et al. 2013). The $B$. oleracea genes were named following the $A$. thaliana nomenclature. We identified a total of 14 candidate genes as potentially involved in ABA biosynthesis in B. oleracea on the basis of their homology to known genes of $A$. thaliana (9) and B. rapa (15) (Fig. 2). These consisted of two zeaxanthin epoxidase (ZEP, also called $A B A 1)$-like sequences (BoABA1.1 and BoABA1.2), one xanthoxin dehydrogenase (BoABA2), one molybdenum cofactor sulfurase (BoABA3), eight 9-cis-epoxycarotenoid dioxygenases (BoNCED2.1, BoNCED2.2, BoNCED3.1, BoNCED3.2, BoNCED5, BoNCED6, BoNCED9.1 and BoNCED9.2), and two abscisic-aldehyde oxidase (BoAAO3.1 and BoAAO3.2) genes. Likewise, we identified 19 candidate genes for the ET biosynthetic pathway in B. oleracea (Fig. 3). Among these, eleven and eight were 1-aminocyclopropane-1-carboxylic-acid synthase (BoACS2, BoACS5.1, BoACS5.2, BoACS6, BoACS7.1, BoACS7.2, BoACS8.1, BoACS8.2, BoACS9.1, BoACS9.2 and BoACS11) and aminocyclopropane-1-carboxylateoxidase (BoACO1.1, BoACO1.2, BoACO2.1, BoACO2.2, BoACO3.1, BoACO3.2, BoACO4 and BoACO5)-like genes, respectively.

\section{ABA and ET biosynthetic genes are closely related among Brassicaceae}

Next, we constructed a microsynteny map of the orthologous ABA and ET biosynthesis genes among $B$. oleracea, B. rapa and A. thaliana (Fig. 4) to understand the evolutionary relationships among them. There were 26 orthologous gene pairs (9 ABA and 12 ET biosynthesis-related) between $B$. oleracea and A. thaliana, and 36 pairs (14 ABA and 19 ET biosynthesis) between $B$. oleracea and B. rapa. This result revealed that the $B$. 
oleracea genes related to both $\mathrm{ABA}$ and ET biosynthesis are closely related to those of $B$. rapa and $A$. thaliana.

We performed an initial check of the expression of the selected putative candidate

ABA and ET biosynthesis genes using the fragments per kilobase of transcript per million mapped reads (FPKM) values of the ornamental cabbage transcriptome data previously

\section{FPKM analysis shows differences in ABA and ET biosynthetic gene expression between} green and purple leaves reported by our laboratory (Jin et al. 2018a) (Fig. 5, 6 and Table S1). Among the ABA biosynthetic genes, five genes, including BoNCED2.1 (Bo1037062), BoNCED2.2 (Bol009433), BoNCED6 (Bol007451), BoNCED9.1 (Bo1027485) and BoAAO3.2 (Bol040907), showed a relatively higher expression in purple leaves compared to green leaves, while the opposite pattern was found for the remaining nine genes. As regards ethylene biosynthesis, most of the ethylene biosynthetic genes showed a relatively higher expression in purple compared to green leaves of both ornamental cabbage lines, with the exception being BoACO3.2 (Bo1010411). Among the ACS genes, however, six were not expressed in either line: BoACS2 (Bol040692), BoACS5.1 (Bol008070), BoACS5.2 (Bol005726), BoACS7.1 (Bol042277), BoACS7.2 (Bol039610) and BoACS9.2 (Bol037340).

\section{RT-qPCR analysis confirms gene expression differences between green and purple} leaves

We further selected 15 candidate genes based on RNA-seq expression (FPKM value) data to determine their expression pattern by qRT-PCR (Fig. 7 and 8). The expression of five genes related to ABA biosynthesis, BoNCED2.1 (Bo1037062), BoNCED2.2 (Bo1009433), BoNCED6 (Bol007451), BoNCED9.1 (Bo1027485) and BoAAO3.2 (Bol040907), was 
significantly higher in inner purple leaves compared to the outer green ones. However, the greatest difference in expression levels between purple outer and green inner leaves was found in BoNCED2.1 and BoNCED2.2. The transcript levels of genes related to ET biosynthesis (BoACS6, Bo1006780; BoACS9.1, Bol016984; BoACS11, Bol015102; BoACO1.1, Bol045912; BoACO1.2, Bo1022740; BoACO3.1, Bo1031342; BoACO4, Bo1040946; BoACO5, Bol019026) were significantly higher in purple (inner) leaves compared to green (outer) leaves of purple ornamental cabbage. Nevertheless, the expression of BoACS8.2 (Bo1032729) and BoACO2.2 (Bo1011006) was not significantly different between purple and green leaves. Among these ET biosynthetic genes, BoACS11 and BoACO4 showed the highest expression levels in purple leaves compared with green ones.

\section{Discussion}

In this study, we reported candidate genes putatively involved in ABA and ET biosynthesis, their expression patterns in the inner purple and outer green leaves of ornamental cabbage, and the relation of these expression patterns to anthocyanin production.

The quantification of total anthocyanins revealed a significantly higher anthocyanin level in the purple inner (younger) leaves compared to the outer green (older) leaves of ornamental cabbage (Fig. 1b). The result suggests that leaf age might influence the anthocyanin accumulation in ornamental cabbage. Cevahir et al. (2004) reported higher anthocyanin content in the younger leaves compared with older leaves in an ornamental species (Gazania splendens). We reported a similar result in a previous study on ornamental cabbage, in which we also found higher expression levels of anthocyanin biosynthetic genes, specifically $P A L 2$, C4H2, 4CL1, CHI2, UFGT24 and GTS21, in the purple inner (younger) leaves compared to the outer (older) green leaves (Jin et al. 2018a). In another study with a different variety of ornamental cabbage (Jin et al., 2018b), we also observed the highest total anthocyanin 
content in red as leaves compared to light red and white ones. Moreover, it has been shown that $\mathrm{ABA}$ contents correlate the total anthocyanin levels in the red skin of apple cultivar 'Campbell Redchief' (Li et al. 2018).

Recent research reveals that in addition to the biosynthetic and regulatory genes of anthocyanin biosynthesis, plant hormones also have important roles in anthocyanin production (Reviewed in Kim et al. 2006; He et al. 2010; Jaakola 2013). ABA plays a vital role in plant growth and development and in adaptation to biotic and abiotic stress conditions (Reviewed in Lee and Luan 2012; Vishwakarma et al. 2017). The application of exogenous ABA significantly increases anthocyanin levels, while treatment with nordihydroguaiaretic acid (NDGA), an ABA biosynthetic inhibitor, blocks anthocyanin accumulation in red sweet cherry (Shen et al. 2014). Moreover, ABA treatment improves fruit skin color in addition to increasing the anthocyanin and total phenolic content in the fruit skin of litchi (Lai et al. 2014) and grapes (Koyama et al. 2014; Neto et al. 2017). Several previous studies revealed that the R2R3-MYB TF is the main regulator of anthocyanin biosynthesis in several different plant species, including BoMYB2 in red cabbage (Yuan et al. 2009), BoPAP2 in ornamental cabbage (Jin et al, 2008b), Rosea1, Rosea2, and Venosa in snapdragon (Schwinn et al. 2006), MYB10 in apple (Espley et al. 2009), LcMYB1 in litchi (Lai et al. 2014), DcMYB6 in carrot root (Xu et al. 2017). ABA directly regulates the expression of anthocyanin-promoting $M Y B$ genes at the transcriptional level (Shen et al. 2014; Leng et al. 2014). Shen et al. (2014) found that the transcript level of PacMYBA was 15.2-fold higher in ABA-treated $(2 \mathrm{~h}$ preincubation) than that in NDGA-treated sweet cherry fruits. Moreover, endogenous ABA levels promote color development in strawberry at ripening by accelerating ethylene production and increasing activity of phenylalanine ammonia-lyase $(P A L)$, one of the key enzymes of the anthocyanin biosynthetic pathway (Jiang and Joyce 2003). Our results showed significantly higher transcript levels of ABA biosynthetic genes (BoNCED2.1, 
BoNCED2.2, BoNCED9.1 and BoAAO3.2) in the inner purple leaves compared to the outer

256

257

258

259

260

261

262

263

264

265

266

267

268

269

270

271

272

273

274

275

276

277

278

279 green leaves, suggesting that ABA production is higher in purple leaves (Fig. 7). This suggests that the ABA biosynthetic genes might influence the intense purple pigmentation in the inner leaves of the purple ornamental cabbage. The higher expression of NCED genes is significantly correlated with higher levels of ABA (Soar et al. 2004; Cramer 2010). Furthermore, Shen et al. (2014) have shown that the expression of the structural as well as the regulatory $(P a c M Y B A)$ genes of anthocyanin biosynthesis, as well as PacNCED1, which encodes an enzyme involved in the first step of ABA biosynthesis, was down-regulated in the RNAi fruit sections compared to the control in sweet cherry fruit. Ornamental cabbage is usually grown during winter, and $\mathrm{ABA}$ is known to be involved in adaptation to environmental stresses, including cold (Baron et al. 2012; Vishwakarma et al. 2017). It is well-known that cold stress can mildly increase the endogenous ABA level in the plants (Miura and Furumoto 2013). Therefore, it is possible that the younger inner leaves might have increased ABA biosynthesis under cold stress, resulting in the deep purple coloration of these inner leaves. Anthocyanin levels are promoted by low temperature (Leyva et al. 1995), and anthocyanins are reported to assist plants in adapting to and resisting environmental stresses, such as exposure to UV light, cold, drought, pests and diseases (Bi et al. 2018). Abiotic-stress-induced anthocyanins are known to act as reactive oxygen species (ROS) inhibitors and photoprotectants (Kovinich et al. 2015).

The plant hormone ET also promotes anthocyanin production. El-Kereamy et al. (2003) have shown that the exogenous application of an ET-releasing compound (such as 2-chloroethylphosphonic acid, 2-CEPA) on grape berries (cv. 'Cabernet Sauvignon') at veraison (the onset of ripening) enhances the anthocyanin content and skin color, while application of 1-methylcyclopropene (1-MCP) decreased ethylene production via blocking of the ethylene receptors. They also found that ET can activate the transcription of the structural 
genes in the anthocyanin biosynthetic pathway (El-Kereamy et al. 2003). In this study, we found a relatively higher expression of ET biosynthetic genes in inner purple (younger) leaves compared to outer green (older) ones (Fig. 8). The higher transcript levels of ET biosynthetic genes might be due to a cold response. It has been demonstrated that low temperature $\left(2{ }^{\circ} \mathrm{C}\right)$ treatment enhanced ET levels in carnation (Barrowclough et al. 1991). Furthermore, the expression of ET biosynthetic genes might vary along with leaf developmental stages. Rodrigues-Pousada et al. (1993) also reported that the expression of ACS1 was higher in younger tissues including young leaves in Arabidopsis.

Both ABA and ET biosynthesis were regulated by the environmental stresses, including cold (Berens et al. 2019; Shinshi 2008). Plants show differential stress responses, depending on the age and developmental stages (Berens et al. 2019). In Arabidopsis, it has been shown that younger leaves had higher levels of salicylic acid and immunity to stress compared to older leaves (Berens et al. 2019). The ethylene responsive factor (ERF), an ET inducible $\mathrm{TF}$ that regulates the transcription of stress responsive as well as ABA biosynthesis-related genes via interacting with various cis-elements and promotes plant responses to stress (Chen and Zhu 2004; Wu et al. 2007). In Arabidopsis, three CBF genes belonging to the ethylene-responsive element binding factor/AP2-type TF family are induced within a short period of exposure to cold stress (Gilmour et al. 1999) and stimulate transcription of cold-regulated genes (COR) via binding the promoter region (Zhao et al. 2009; Stockinger et al. 1997). The ET and JA signaling pathways can regulate the $C B F$ genes (reviewed in Shi et al. 2015). Anyway, although ET has been associated in cold stress response, the precise role of this hormone in cold tolerance m remains largely unknown (Shi et al. 2012). ET signaling seems to negatively regulate the cold tolerance in Arabidopsis (Shi et al. 2012) while in tomato, transgenic plants overexpressing LeERF2 exhibited an enhanced cold tolerance (Zhang and Huang 2010). Moreover, ET can induce the anthocyanin 
accumulation in apple skin during fruit ripening (Faragher and Brohier 1984; An et al. 2018).

306

307

308

309

310

311

312

313

314

315

316

317

A crosstalk between ABA and ET is also known to operate in a synergic manner in the production of anthocyanin (Wang et al. 2007).

The central core of the ornamental cabbage turn purple in response to the low temperature the plant is sensing. Probably, the cold stress triggers the up-regulation of a various array of defense responses acted by the plant in order to cope with the low temperatures, stimulating the acquisition of a cold tolerance phenotype. These defenses might belong to the ET and ABA domains. The reason why only the inner leaves are purplish is due to their intrinsic vulnerability correlated to their young age. The young inner leaves arranged in the central rosette are more prone to develop chilling injuries, therefore they might accumulate secondary metabolites including anthocyanin with a protective effect in order to scavenge the ROS generated by the increased permeability of the chloroplast membrane. Moreover, the chloroplasts present in the tissues that are experiencing the cold stress are also more vulnerable to the light stress as they already weakened by the cold stress itself, so in order to avoid an excess of visible light the production of a photoprotective anthocyanic screen seems to be an affordable solution to the problem. The purple color is disappear as leaves become mature (outer leaves), and more resistant because of a thicker cutin, higher concentration of soluble solid and development of cold tolerant traits. Mature leaves will turn green, becoming photosynthetically active and sustaining the plant growth.

\section{Conclusions}

We identified 14 and 19 putative candidate genes involved in ABA and ET biosynthesis, respectively, in the purple ornamental cabbage Brassica oleracea var. acephala via an intensive phylogenetic analysis. RNA-seq (FPKM value) and RT-qPCR analysis of the expression patterns of these genes indicated that the ABA biosynthetic genes BoNCED2.1 
and BoNCED2.2 and the ET biosynthetic genes BoACS11 and BoACO4 were strongly expressed in the purple inner younger leaves compared to the green outer older leaves. These findings correlate the expression of these plant hormone biosynthetic genes with the intense purple pigmentation in the younger inner leaf of purple ornamental cabbage. Therefore, the cross-link between ABA-ET signaling components might provide a possible clue for differential anthocyanin biosynthesis in purple inner and outer green leaves of the same ornamental cabbage.

\section{Conflict of interest}

The authors declare no conflict of interest.

Acknowledgements

This research was supported by the Golden Seed Project (Center for Horticultural

Seed Development, Grant no. 213007-05-3-CG100) of the Ministry of Agriculture, Food and Rural Affairs in the Republic of Korea (MAFRA).

\section{Author contribution}

ISN, JGK, JIP, HTK and MAR designed the experiments. JSW conducted the experiments. HJJ and KSA contributed to the experiments. MAR performed the bioinformatics analysis. JSW and MAR analyzed the experimental data. MAR wrote the manuscript. All authors read and approved the manuscript.

\section{References}

Allan, A.C., Hellens, R.P., and William, Laing, A. 2008. MYB transcription factors that colour our fruit. Trends Plant Sci. 13(3): 99-102. doi:10.1016/J.TPLANTS.2007.11.012. 
An, J.P., Yao, J.F., Xu, R.R., You, C.X., Wang, X.F., and Hao, Y.J. 2018. Apple bZIP transcription factor MdbZIP44 regulates abscisic acid-promoted anthocyanin accumulation. Plant Cell Environ. 41(11): 2678-2692. doi:10.1111/pce.13393.

An, J.P., Wang, X.F., Li, Y.Y., Song, L.Q., Zhao, L.L., You, C.X. and Hao, Y.J. 2018. EIN3LIKE1, MYB1, and ETHYLENE RESPONSE FACTOR3 act in a regulatory loop that synergistically modulates ethylene biosynthesis and anthocyanin accumulation. Plant Physiol. 178(2): 808-823. doi: 10.1104/pp.18.00068.

Baron, K.N., Schroeder, D.F., and Stasolla, C. 2012. Transcriptional response of abscisic acid (ABA) metabolism and transport to cold and heat stress applied at the reproductive stage of development in Arabidopsis thaliana. Plant Sci. 188: 48-59. doi:10.1016/J.PLANTSCI.2012.03.001.

Barrowclough, P.M., Field, R.J., and Farr, D.J. 1991. Coolstorage enhances ethylene production and reduces vase life of carnation flowers. New Zeal. J. Crop Hortic. Sci. 19(2): 191-197. doi:10.1080/01140671.1991.10421798.

Baudry, A., Caboche, M., and Lepiniec, L. 2006. TT8 controls its own expression in a feedback regulation involving TTG1 and homologous MYB and bHLH factors, allowing a strong and cell-specific accumulation of flavonoids in Arabidopsis thaliana. Plant J. 46(5): 768-779. doi:10.1111/j.1365-313X.2006.02733.x.

Berens, M.L., Wolinska, K.W., Spaepen, S., Ziegler, J., Nobori, T., Nair, A., et al. 2019. Balancing trade-offs between biotic and abiotic stress responses through leaf agedependent variation in stress hormone cross-talk. Proc. Natl. Acad. Sci. 116(6): 23642373. doi.org/10.1073/pnas.1817233116.

Bergfeldt, B. 2013. Try kale for vitamin K and cancer protection. Tufts Univ. Heal. Nutr. Lett. 31(5): 6. Available from https://search.proquest.com/openview/aec7d18eadba401622b5e3bfac30819f/1?pq- 

origsite $=$ gscholar\&cbl $=30886$ [accessed 4 June 2018].

Bi, H., Guo, M., Wang, J., Qu, Y., Du, W., and Zhang, K. 2018. Transcriptome analysis reveals anthocyanin acts as a protectant in Begonia semperflorens under low temperature. Acta Physiol. Plant. 40(1): 10. doi:10.1007/s11738-017-2578-3.

Booker, M.A., and DeLong, A. 2015. Producing the ethylene signal: Regulation and diversification of ethylene biosynthetic enzymes. Plant Physiol. 169(1): 42-50. doi:10.1104/pp.15.00672.

Cevahir, G., Yentur, S., Yazgan, M., Unal, M., and Yilmazer, N. 2004. Peroxidase activity in relation to anthocyanin and chlorophyll content in juvenile and adult leaves of "Ministar" Gazania splendens. Pakistan J. Bot. 36(3): 603-610.

Chalker-Scott, L. 1999. Environmental significance of anthocyanins in plant stress responses. Photochem. Photobiol. 70(1): 1-9. doi:10.1111/j.1751-1097.1999.tb01944.x.

Chen, W.J., and Zhu, T. 2004. Networks of transcription factors with roles in environmental stress response. Trends Plant Sci. 9: 591-596. doi:10.1016/j.tplants.2004.10.007.

Christie, P.J., Alfenito, M.R., and Walbot, V. 1994. Impact of low-temperature stress on general phenylpropanoid and anthocyanin pathways: Enhancement of transcript abundance and anthocyanin pigmentation in maize seedlings. Planta 194(4): 541-549. Available from https://link.springer.com/content/pdf/10.1007\%2FBF00714468.pdf [accessed 11 October 2018].

Cramer, G.R. 2010. Abiotic stress and plant responses from the whole vine to the genes. Aust. J. Grape Wine Res. 16: 86-93. doi:10.1111/j.1755-0238.2009.00058.x.

Das, P.K., Shin, D.H., Choi, S.B., and Park, Y.I. 2012. Sugar-hormone cross-talk in anthocyanin biosynthesis. Mol. Cells 34(6): 501-507. doi:10.1007/s10059-012-0151-x.

Deikman, J., and Hammer, P.E. 1995. Induction of anthocyanin accumulation by cytokinins in Arabidopsis thaliana. Plant Physiol. 108(1): 47-57. doi:10.1104/PP.108.1.47. 
Deluc, L., Barrieu, F., Marchive, C., Lauvergeat, V., Decendit, A., Richard, T., et al. 2006. Characterization of a grapevine R2R3-MYB transcription factor that regulates the phenylpropanoid pathway. Plant Physiol. 140(2): 499-511. doi:10.1104/pp.105.067231.

El-Kereamy, A., Chervin, C., Roustan, J.P., Cheynier, V., Souquet, J.M., Moutounet, M., et al. 2003. Exogenous ethylene stimulates the long-term expression of genes related to anthocyanin biosynthesis in grape berries. Physiol. Plant. 119(2): 175-182. doi:10.1034/j.1399-3054.2003.00165.x.

Espley, R.V., Brendolise, C., Chagné, D., Kutty-Amma, S., Green, S., Volz, R., et al. 2009. Multiple repeats of a promoter segment causes transcription factor autoregulation in red apples. Plant Cell 21(1): 168-83. doi:10.1105/tpc.108.059329.

Faragher, J.D. and Brohier, R.L. 1984. Anthocyanin accumulation in apple skin during ripening: regulation by ethylene and phenylalanine ammonia-lyase. Sci. Hortic. 22(1-2): 89-96. https://doi.org/10.1016/0304-4238(84)90087-6.

Fetouh, M.I. 2018. Edible Landscaping in Urban Horticulture. Springer, Cham. pp. 141-173. doi:10.1007/978-3-319-67017-1_7.

Gilmour, S.J., Zarka, D.G., Stockinger, E.J., Salazar, M.P., Houghton, J.M. and Thomashow, M.F. 1998. Low temperature regulation of the Arabidopsis CBF family of AP2 transcriptional activators as an early step in cold-induced COR gene expression. Plant J. 16(4): 433-442. https://doi.org/10.1046/j.1365-313x.1998.00310.x

Goodstein, D.M., Shu, S., Howson, R., Neupane, R., Hayes, R.D., Fazo, J., et al. 2011. Phytozome: a comparative platform for green plant genomics. Nucleic Acids Res. 40(D1): D1178-D1186. https://doi.org/10.1093/nar/gkr944.

Gyula, P., Schäfer, E., and Nagy, F. 2003. Light perception and signalling in higher plants. Curr. Opin. Plant Biol. 6(5): 446-452. doi:10.1016/S1369-5266(03)00082-7. He, F., Mu, L., Yan, G.L., Liang, N.N., Pan, Q.H., Wang, J., et al. 2010. Biosynthesis of 
anthocyanins and their regulation in colored grapes. Molecules 15(12): 9057-9091. doi:10.3390/molecules 15129057 .

Huaiming, W., Guangchen D., Cuiying J., Xuewen T., and Xian W. 1995. In vitro propagation of ornamental kale (Brassica oleracea var. acephala f. tricolor Hort.). Acta Agric. Boreali Sin. 10(1): 64-69. Available from http://en.cnki.com.cn/Article_en/CJFDTOTAL-HBNB501.012.htm [accessed 25 April 2018].

Jaakola, L. 2013. New insights into the regulation of anthocyanin biosynthesis in fruits. Trends Plant Sci. 18: 477-483. doi:10.1016/j.tplants.2013.06.003.

Ji, X.H., Wang, Y.T., Zhang, R., Wu, S.J., An, M.M., Li, M., et al. 2015. Effect of auxin, cytokinin and nitrogen on anthocyanin biosynthesis in callus cultures of red-fleshed apple (Malus sieversii f. niedzwetzkyana). Plant Cell, Tissue Organ Cult. 120(1): 325337. doi:10.1007/s11240-014-0609-y.

Jiang, Y., and Joyce, D.C. 2003. ABA effects on ethylene production, PAL activity, anthocyanin and phenolic contents of strawberry fruit. Plant Growth Regul. 39(2): 171174. doi:10.1023/A:1022539901044.

Jin, S.W., Rahim, M.A., Afrin, K.S., Park, J.I., Kang, J.G., and Nou, I.S. 2018 a. Transcriptome profiling of two contrasting ornamental cabbage (Brassica oleracea var. acephala) lines provides insights into purple and white inner leaf pigmentation. BMC Genomics 19(1): 797. doi:10.1186/s12864-018-5199-3.

Jin, S.W., Rahim, M.A., Kim, H.T., Park, J.I., Kang, J.G., and Nou, I.S. 2018b. Molecular analysis of anthocyanin-related genes in ornamental cabbage. Genome 61(2): 111-120. doi:10.1139/gen-2017-0098.

Kim, J.S., Lee, B.H., Kim, S.H., Oh, K.H., and Cho, K.Y. 2006. Responses to environmental and chemical signals for anthocyanin biosynthesis in non-chlorophyllous corn (Zea mays 

L.) leaf. J. Plant Biol. 49(1): 16-25. doi:10.1007/BF03030784.

Kovinich, N., Kayanja, G., Chanoca, A., Otegui, M.S., and Grotewold, E. 2015. Abiotic stresses induce different localizations of anthocyanins in Arabidopsis. Plant Signal. Behav. 10(7): e1027850. doi:10.1080/15592324.2015.1027850.

Koyama, R., de Assis, A.M., Yamamoto, L.Y., Borges, W.F., de Sá Borges, R., Prudêncio, S.H., and Roberto, S.R. 2014. Exogenous abscisic acid increases the anthocyanin concentration of berry and juice from "Isabel” grapes (Vitis labrusca L.). HortScience 49(4): 460-464.

Krzywinski, M., Schein, J., Birol, I., Connors, J., Gascoyne, R., Horsman, D., et al. 2009. Circos: an information aesthetic for comparative genomics. Genome Res. 19(9): 16391645. doi:10.1101/gr.092759.109.

Lai, B., Li, X.J., Hu, B., Qin, Y.H., Huang, X.M., Wang, H.-C., and Hu, G.-B. 2014. LcMYB1 is a key determinant of differential anthocyanin accumulation among genotypes, tissues, developmental phases and ABA and light stimuli in Litchi chinensis. PLoS One 9(1): e86293. doi:10.1371/journal.pone.0086293.

Lee, S.C., and Luan, S. 2012. ABA signal transduction at the crossroad of biotic and abiotic stress responses. Plant Cell Environ. 35(1): 53-60. doi:10.1111/j.13653040.2011.02426.x.

Leng, P., Yuan, B., and Guo, Y. 2014. The role of abscisic acid in fruit ripening and responses to abiotic stress. J. Exp. Bot. 65(16): 4577-4588. doi:10.1093/jxb/eru204.

Leyva, A., Jarillo, A., Salinas, J., and Miguel Martinez-Zapater, J. 1995. Low temperature induces the accumulation of phenylalanine ammonia-lyase and chalcone synthase mRNAs of Arabidopsis thaliana in a light-dependent manner'. Plant Physiol. 108(1): 139-446. doi: https://doi.org/10.1104/pp.108.1.39.

Li, W.F., Mao, J., Yang, S.J., Guo, Z.G., Ma, Z.H., Dawuda, M.M., Zuo, C.W., et al. 2018. 
Anthocyanin accumulation correlates with hormones in the fruit skin of 'Red Delicious' and its four generation bud sport mutants. BMC Plant Biol. 18(1): 363. doi:10.1186/s12870-018-1595-8.

Liu, X.P., Gao, B.Z., Han, F.Q., Fang, Z.Y., Yang, L.M., Zhuang, M., et al. 2017. Genetics and fine mapping of a purple leaf gene, $\mathrm{BoPr}$, in ornamental kale (Brassica oleracea $\mathrm{L}$. var. acephala). BMC Genomics 18(1): 230. doi:10.1186/s12864-017-3613-x.

Loreti, E., Povero, G., Novi, G., Solfanelli, C., Alpi, A., and Perata, P. 2008. Gibberellins, jasmonate and abscisic acid modulate the sucrose-induced expression of anthocyanin biosynthetic genes in Arabidopsis. New Phytol. 179(4): 1004-1016. doi:10.1111/j.14698137.2008.02511.x.

Mehrtens, F. 2005. The Arabidopsis transcription factor MYB12 is a flavonol-specific regulator of phenylpropanoid biosynthesis. Plant Physiol. 138(2): 1083-1096. doi:10.1104/pp.104.058032.

Middleton, E., Kandaswami, C., and Harborne, J. 1993. The Flavonoids Advances in Research Since 1986. Chapman and Hall, London.

Miura, K., and Furumoto, T. 2013. Cold signaling and cold response in plants. Int. J. Mol. Sci. 14(3): 5312-5337. doi:10.3390/ijms14035312.

Mol, J., Grotewold, E., and Koes, R. 1998. How genes paint flowers and seeds. Trends Plant Sci. 3(6): 212-217. Elsevier Current Trends. doi:10.1016/S1360-1385(98)01242-4.

Neto, F.J.D., Tecchio, M.A., Pimentel, A., Vedoato, B.T.F., Lima, G.P.P., and Roberto, S.R. 2017. Effect of ABA on colour of berries, anthocyanin accumulation and total phenolic compounds of "Rubi” table grape ('Vitis vinifera'). Aust. J. Crop Sci. 11(2): 199-205.

Pourcel, L., Routaboul, J., Cheynier, V., Lepiniec, L., and Debeaujon, I. 2007. Flavonoid oxidation in plants: from biochemical properties to physiological functions. Trends Plant Sci. 12(1): 29-36. doi:10.1016/j.tplants.2006.11.006. 
Rahim, M.A., Afrin, K.S., Jung, H.J., Kim, H.T., Park, J.I., Hur, Y., and Nou, I.S. 2019. Molecular analysis of anthocyanin biosynthesis-related genes reveal BoTT8 associated with purple hypocotyl of broccoli (Brassica oleracea var. italica L.). Genome: gen2018-0173. doi:10.1139/gen-2018-0173.

Rahim, M.A., Busatto, N., and Trainotti, L. 2014. Regulation of anthocyanin biosynthesis in peach fruits. Planta 240(5): 913-929. doi:10.1007/s00425-014-2078-2.

Rahim, M.A., Robin, A.H.K., Natarajan, S., Jung, H.J., Lee, J., Kim, H., et al. 2017. Identification and characterization of anthocyanin biosynthesis-related genes in kohlrabi. Appl. Biochem. Biotechnol. 184: 1120-1141. doi:10.1007/s12010-017-2613-2.

Ren, J., Liu, Z., Niu, R., and Feng, H. 2015. Mapping of Re, a gene conferring the red leaf trait in ornamental kale (Brassica oleracea L. var. acephala ). Plant Breed. 134(4): 494500. doi:10.1111/pbr.12286.

Rodrigues-Pousada, R.A., De Rycke, R., Dedonder, A., Van Caeneghem, W., Engler, G., Van Montagu, M. and Van Der Straeten, D., 1993. The Arabidopsis 1-aminocyclopropane-1carboxylate synthase gene 1 is expressed during early development. Plant Cell 5(8): 897-911. doi:https://doi.org/10.1105/tpc.5.8.897.

Schluttenhofer, C., and Yuan, L. 2015. Regulation of specialized metabolism by WRKY transcription factors. Plant Physiol. 167(2): 295-306. doi:10.1104/pp.114.251769.

Schwinn, K. Venail, J., Shang, Y., Mackay, S., Alm, V., Butelli, E., et al. 2006. A small family of MYB-regulatory genes controls floral pigmentation intensity and patterning in the genus Antirrhinum. Plant Cell 18(4): 831-851. doi:10.1105/tpc.105.039255.

Shan, X., Zhang, Y., Peng, W., Wang, Z., and Xie, D. 2009. Molecular mechanism for jasmonate-induction of anthocyanin accumulation in Arabidopsis. J. Exp. Bot. 60(13): 3849-3860. doi:10.1093/jxb/erp223.

Shen, X., Zhao, K., Liu, L., Zhang, K., Yuan, H., Liao, X., et al. 2014. A role for PacMYBA 

in ABA-regulated anthocyanin biosynthesis in red-colored sweet cherry cv. Hong Deng (Prunus avium L.). Plant Cell Physiol. 55(5): 862-880. doi:10.1093/pcp/pcu013.

Shinshi, H. 2008. Ethylene-regulated transcription and crosstalk with jasmonic acid. Plant Sci. 175 (1-2): 18-23. doi:10.1016/j.plantsci.2008.03.017.

Shi, Y., Tian, S., Hou, L., Huang, X., Zhang, X., Guo, H. and Yang, S. 2012. Ethylene signaling negatively regulates freezing tolerance by repressing expression of $C B F$ and type-A ARR genes in Arabidopsis. Plant Cell 24(6): 2578-2595. 10.1105/tpc.112.098640.

Shi, Y., Ding, Y. and Yang, S. 2014. Cold signal transduction and its interplay with phytohormones during cold acclimation. Plant Cell Physiol. 56(1): 7-15. doi:10.1093/pcp/pcu.

Soar, C.J., Speirs, J., Maffei, S.M., and Loveys, B.R. 2004. Gradients in stomatal conductance, xylem sap ABA and bulk leaf ABA along canes of Vitis vinifera cv. Shiraz: molecular and physiological studies investigating their source. Funct. Plant Biol. 31(6): 659. doi:10.1071/FP03238.

Stockinger, E.J., Gilmour, S.J. and Thomashow, M.F. 1997. Arabidopsis thaliana CBF1 encodes an AP2 domain-containing transcriptional activator that binds to the $\mathrm{C}$ repeat/DRE, a cis-acting DNA regulatory element that stimulates transcription in response to low temperature and water deficit. Proc. Natl. Acad. Sci. 94(3): 1035-1040. https://doi.org/10.1073/pnas.94.3.1035.

Tamura K., Stecher G., Peterson D., Filipski A., and Kumar S. 2013. MEGA6: Molecular Evolutionary Genetics Analysis version 6.0. Mol. Biol. Evol. 30(12): 2725-2729. doi:https://doi.org/10.1093/molbev/mst197.

Vishwakarma, K., Upadhyay, N., Kumar, N., Yadav, G., Singh, J., Mishra, R.K., et al. 2017. Abscisic acid signaling and abiotic stress tolerance in plants: A review on current knowledge and future prospects. Front. Plant Sci. 8: 161. doi:10.3389/fpls.2017.00161. 
555

556

557

558

559

560

561

562

563

564

565

566

567

568

569

570

571

572

573

574

575

576

577

578

579

Wang, H., Huang, H. and Huang, X., 2007. Differential effects of abscisic acid and ethylene on the fruit maturation of Litchi chinensis Sonn. Plant Growth Regulation, 52(3), pp.189-198. doi:10.1007/s10725-007-9189-8.

Wang, Y., Tong, Y., Li, Y., Zhang, Y., Zhang, J., Feng, J., and Feng, H. 2011. High frequency plant regeneration from microspore-derived embryos of ornamental kale (Brassica oleracea L. var. acephala). Sci. Hortic. 130(1): 296-302. doi:10.1016/j.scienta.2011.06.029.

Wei, Z., Qiang, F., Xigang, D., and Manzhu, B. 2008. The culture of isolated microspores of ornamental kale (Brassica oleracea var. acephala) and the importance of genotype to embryo regeneration. Sci. Hortic. 117(1): 69-72. doi:10.1016/j.scienta.2008.03.023.

Wu, L., Chen, X., Ren, H., Zhang, Z., Zhang, H., Wang, J., et al. 2007. ERF protein JERF1 that transcriptionally modulates the expression of abscisic acid biosynthesis-related gene enhances the tolerance under salinity and cold in tobacco. Planta 226(4): 815-825. doi:10.1007/s00425-007-0528-9.

Xu, Z.S., Feng, K., Que, F., Wang, F., and Xiong, A.S. 2017. A MYB transcription factor, DcMYB6, is involved in regulating anthocyanin biosynthesis in purple carrot taproots. Sci. Rep. 7: 45324. doi:10.1038/srep45324.

Yu, J., Zhao, M., Wang, X., Tong, C., Huang, S., Tehrim, S., et al. 2013. Bolbase: a comprehensive genomics database for Brassica oleracea. BMC Genomics 14(1): 664. https://doi.org/10.1186/1471-2164-14-664.

Yuan, Y., Chiu, L.W., and Li, L. 2009. Transcriptional regulation of anthocyanin biosynthesis in red cabbage. Planta 230(6): 1141-1153. doi:10.1007/s00425-009-1013-4.

Zhang, B., Hu, Z., Zhang, Y., Li, Y., Zhou, S., and Chen, G. 2012. A putative functional MYB transcription factor induced by low temperature regulates anthocyanin biosynthesis in purple kale (Brassica oleracea var. acephala f. tricolor). Plant Cell Rep. 

31(2): 281-289. doi:10.1007/s00299-011-1162-3.

581 Zhang, Z. and Huang, R. 2010. Enhanced tolerance to freezing in tobacco and tomato overexpressing transcription factor TERF2/LeERF2 is modulated by ethylene biosynthesis. Plant Mol. Boil., 73(3): 241-249. doi: 10.1007/s11103-010-9609-4.

Zhang, Y., Liu, Y., Hu, W., Sun, B., Chen, Q., and Tang, H. 2018. Anthocyanin accumulation and related gene expression affected by low temperature during strawberry coloration. Acta Physiol. Plant. 40(11): 192. doi:10.1007/s11738-018-2767-8. participate in the regulation of $L e C B F 1$ gene expression in postharvest tomato fruits. FEBS Lett. 583(20): 3329-3334. doi:10.1016/j.febslet.2009.09.029. 
Table 1. List of primers used in the qRT-PCR analysis.

\begin{tabular}{|c|c|c|c|c|c|}
\hline $\begin{array}{l}\text { Sl. } \\
\text { no. }\end{array}$ & Gene name & Forward primers $\left(5^{\prime}-3^{\prime}\right)$ & Reverse primers (5'-3') & Gene accession & $\begin{array}{l}\text { Amplicon } \\
\text { length (bp) }\end{array}$ \\
\hline 1 & BoNCED2.1 & TTGGGGATAATGCCGAAAGACG & ATAGAATCCGCCGGCGACATACAC & Bol037062 & 155 \\
\hline 2 & BoNCED2.2 & CGTAACGGCGCAAATCCAATG & GAAAACCGGTCTACCCAATCGTGT & Bol009433 & 168 \\
\hline 3 & BoNCED6 & AACCCGCCCGATACGATTTTCAG & CCTTCCGGTTCGTTTCTTTTGTCC & Bol007451 & 100 \\
\hline 4 & BoNCED9.1 & CACGTGGGCTTTTCGGTTTACTCG & TCTCCGGTTTGGGTGACTTTGACG & Bol027485 & 139 \\
\hline 5 & BоAAO3.2 & GTCCGAGCAGAACGTCCTTGAG & CCAGCAGCTTCCGTGTAAAACTTG & Bol040907 & 169 \\
\hline 6 & BoACS6 & GAGTTTATCAGCGTCGCAGAAGTA & CCACCCGGTCATTGTAAGAGTA & Bol006780 & 142 \\
\hline 7 & BoACS8.2 & ACAACAACCCGAACCGAACTAAAC & TGAAACCAGGAGAAGCGAAAACAG & Bol032729 & 112 \\
\hline 8 & BoACS9.1 & TGGCGATGCAAAGGCTCAAAGAA & TCATCAGGTACACGGTCGGTCCAT & Bol016984 & 151 \\
\hline 9 & BoACS11 & TCAGCGGCGACCAAAATGT & AACCCGAAACCAACCTGTCTCTT & Bol015102 & 154 \\
\hline 10 & BoACO1.1 & GGTTCCTATCCCGCCATCA & ACAGCACTTTTGTATCTCCCATTA & Bol045912 & 93 \\
\hline 11 & BoACO1.2 & ATGAGGAGCATTTGAAAGAGAAGT & TTATGCCAAACGAAGAAAGTGC & Bol022740 & 109 \\
\hline 12 & BoACO2.2 & CCAACGGCAGGTACAAGAGTG & TTTACAGGCAAGCGATGAAGC & Bol011006 & 131 \\
\hline 13 & BoACO3.1 & CAACGGGAAGTACAAGAGCATAAT & CGCATCACTTCCAGGGTTGTA & Bol031342 & 97 \\
\hline 14 & $\mathrm{BoACO4}$ & GGCGGCATCATCCTCCTCTTC & TCCACGCTCTTGTACTTCCCATTG & Bol040946 & 158 \\
\hline 15 & BoACO5 & CGATGTTCAGCCGACGCCTAATG & TTTCCTTCCTCCCTCGCCAACAC & Bol019026 & 117 \\
\hline 16 & BoActin $^{*}$ & CTGAGGAGCACCCGGTTCTTCTTA & CGGAGGATGGCGTGTGGTAGA & Bol003004 & 238 \\
\hline
\end{tabular}

*, BoActin primer sequences were previously reported by Rahim et al. (2017). 


\section{List of Figures}

Fig. 1. Phenotype of purple ornamental cabbage line (SCNU-OC-41-102) used in this study

(a). The circles indicate the sampling areas for RNA extraction and pigment quantification.

Total anthocyanin contents in inner purple and outer green leaves (b).

Fig. 2. A phylogenetic tree showing the putative abscisic acid (ABA) biosynthetic genes of Brassica oleracea and their homologs in Arabidopsis thaliana and B. rapa. The tree was built by the maximum-likelihood method using 1000 bootstrap values with MEGA6.0 software (Tamura et al. 2013). The deduced amino acid sequences of these plant species were obtained from 'Bolbase' 'Phytozome' and 'TAIR'. The green, red and grey circles denote ABAbiosynthetic genes of $A$. thaliana, B. oleracea and B. rapa, respectively. The accessions are shown in parentheses for each gene.

Fig. 3. Phylogenetic analysis of putative ethylene biosynthetic genes in B. oleracea and their homologs from A. thaliana, B. oleracea and B. rapa. The trees were constructed by the neighbor-joining method using 1000 bootstrap values with MEGA6.0 software (Tamura et al. 2013). The deduced amino acid sequences of these plant species were obtained from 'Bolbase' 'Phytozome' and 'TAIR'. The green, red and grey circles indicate ethylene biosynthetic genes in A. thaliana, B. oleracea and B. rapa, respectively. The accessions are shown in parenthesis for each gene.

Fig. 4. Microsynteny analysis of abscisic acid (ABA)- and ethylene (ET)-biosynthesis-related genes among B. oleracea, B. rapa and A. thaliana. The orange, green and blue colors denote B. oleracea, B. rapa and A. thaliana chromosomes, respectively.

Fig. 5. Heatmap illustration of the expression pattern of abscisic acid (ABA) biosynthetic genes in purple and green ornamental cabbage lines based on the FPKM data obtained through RNA sequencing of purple (inner) and green (outer) leaves of ornamental cabbage. The red and blue boxes designate the highest and the lowest expression values, respectively. 
620 Fig. 6. Heatmap illustration of the expression pattern of ethylene biosynthetic genes in purple 621 and green ornamental cabbage lines based on the FPKM data obtained through RNA 622 sequencing of purple (inner) and green (outer) leaves of ornamental cabbage. The red, blue 623 and white boxes designate the highest values, the lowest values, and no expression, 624 respectively.

625 Fig. 7. Expression profiles of abscisic acid (ABA) biosynthetic genes by qRT-PCR in purple 626 (inner) and green (outer) leaves of ornamental cabbage. Error bars represent \pm SE of the 627 means of triplicates. Letters above the bars indicate significant differences.

628 Fig. 8. Expression profiles of ethylene biosynthetic genes by qRT-PCR in purple (inner) and 629 green (outer) leaves of ornamental cabbage. Error bars represent $\pm \mathrm{SE}$ of the means of 630 triplicates. Letters above the bars indicate significant differences. 
a)

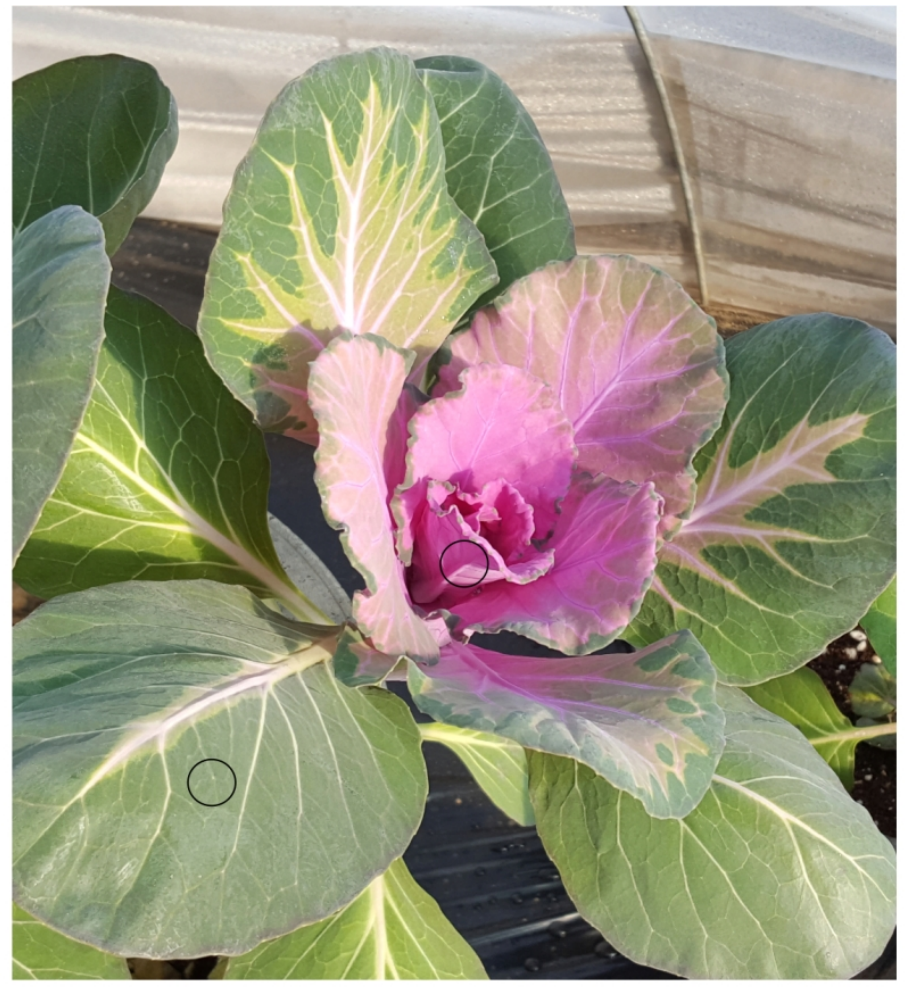

b)

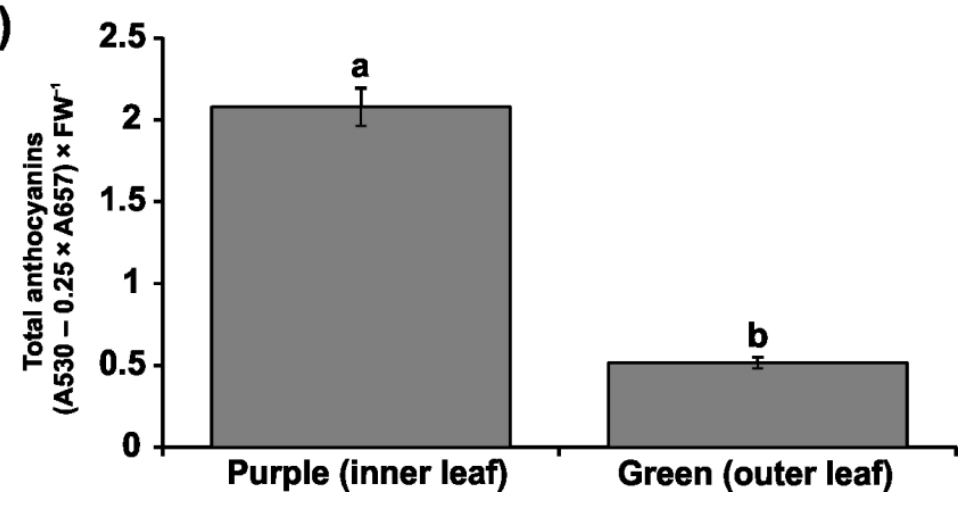

Fig. 1. Phenotype of purple ornamental cabbage line (SCNU-OC-41-102) used in this study (a). The circles indicate the sampling areas for RNA extraction and pigment quantification. Total anthocyanin contents in inner purple and outer green leaves (b). 


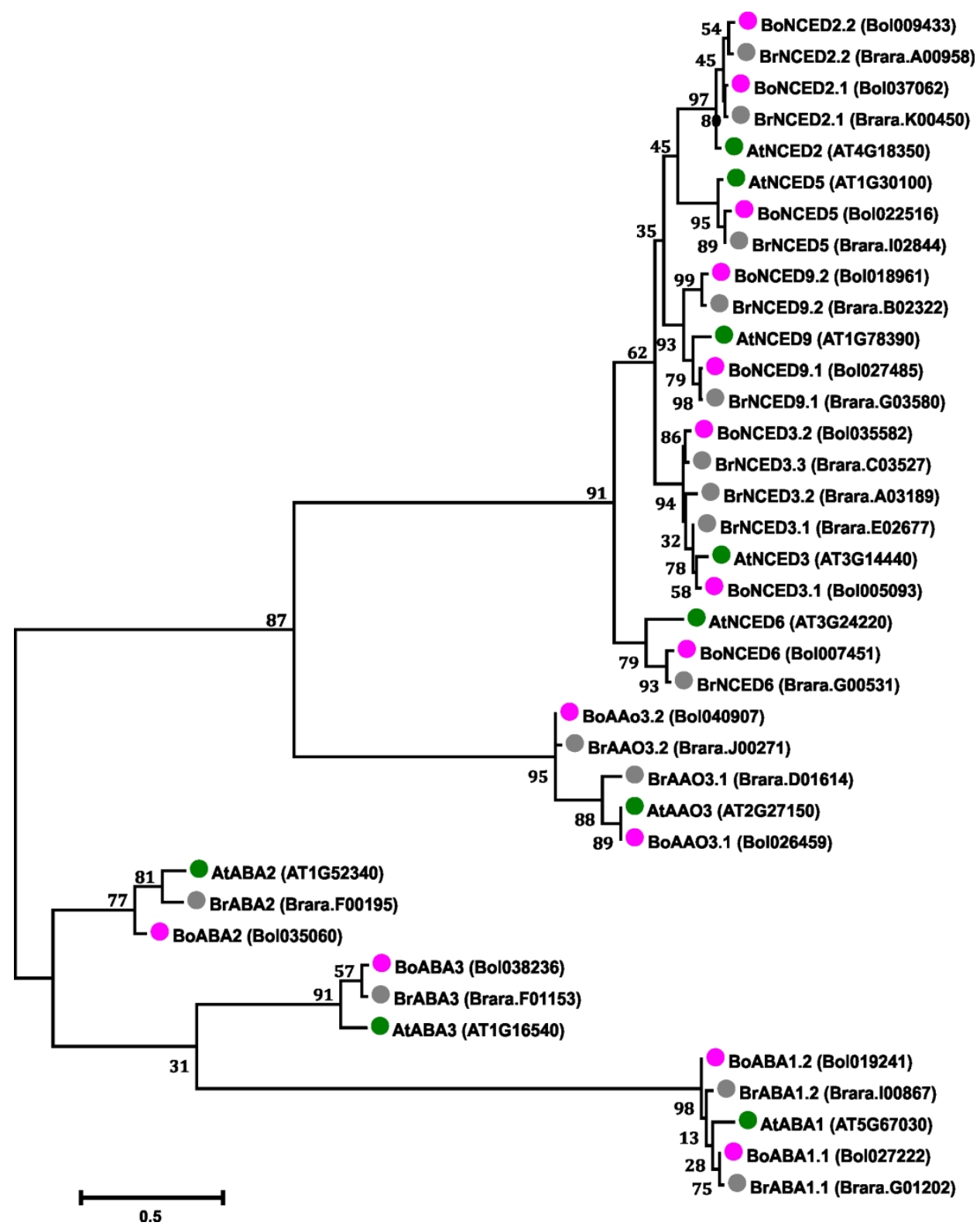

Fig. 2. A phylogenetic tree showing the putative abscisic acid (ABA) biosynthetic genes of Brassica oleracea and their homologs in Arabidopsis thaliana and B. rapa. The tree was built by the maximum-likelihood method using 1000 bootstrap values with MEGA6.0 software (Tamura et al. 2013). The deduced amino acid sequences of these plant species were obtained from 'Bolbase' 'Phytozome' and 'TAIR'. The green, red and grey circles denote $A B A$-biosynthetic genes of $A$. thaliana, $B$. oleracea and $B$. rapa, respectively. The accessions are shown in parentheses for each gene. 


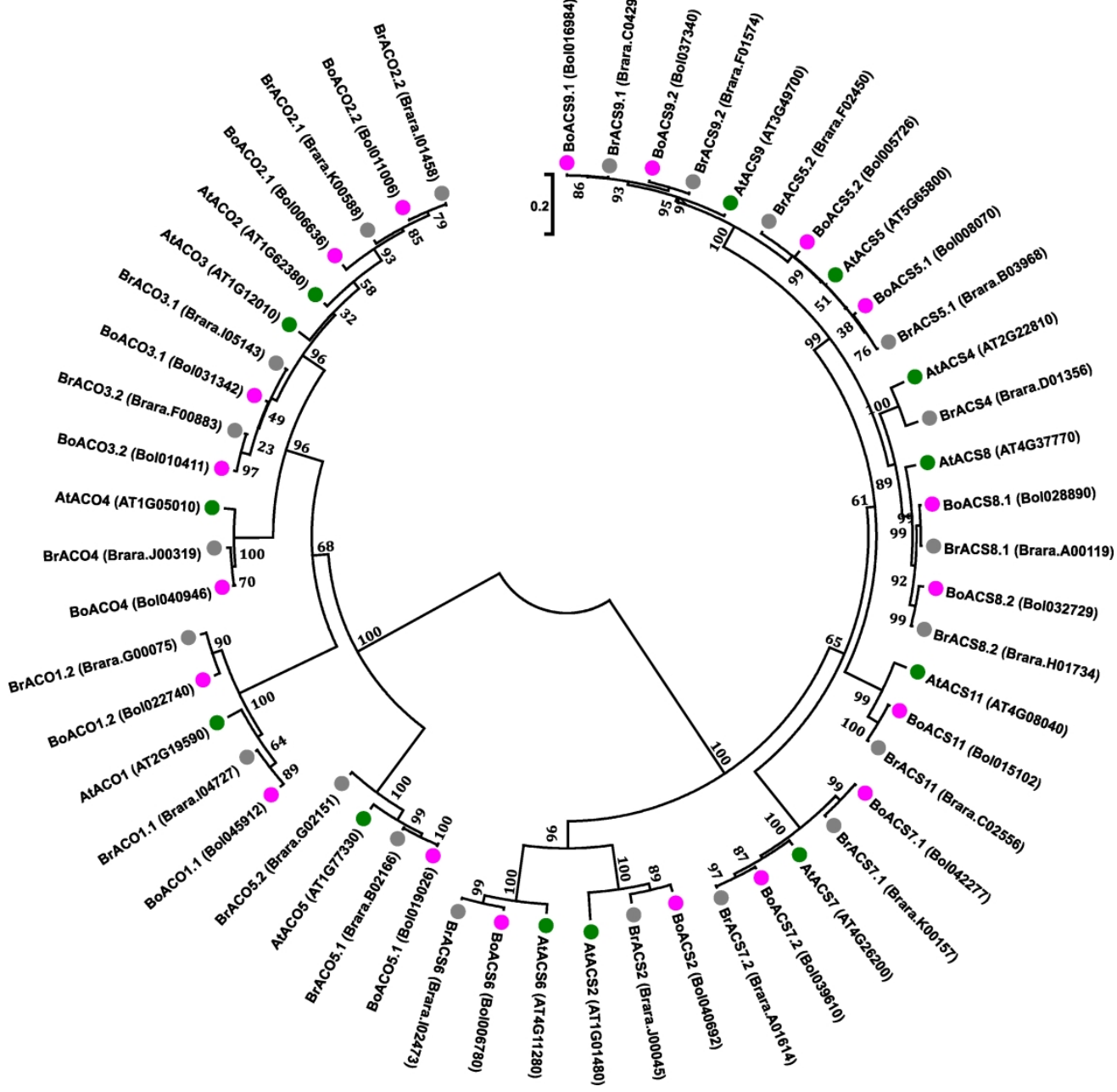

Fig. 3. Phylogenetic analysis of putative ethylene biosynthetic genes in B. oleracea and their homologs from A. thaliana, B. oleracea and B. rapa. The trees were constructed by the neighbor-joining method using 1000 bootstrap values with MEGA6.0 software (Tamura et al. 2013). The deduced amino acid sequences of these plant species were obtained from 'Bolbase' 'Phytozome' and 'TAIR'. The green, red and grey circles indicate ethylene biosynthetic genes in A. thaliana, B. oleracea and B. rapa, respectively. The accessions are shown in parenthesis for each gene. 


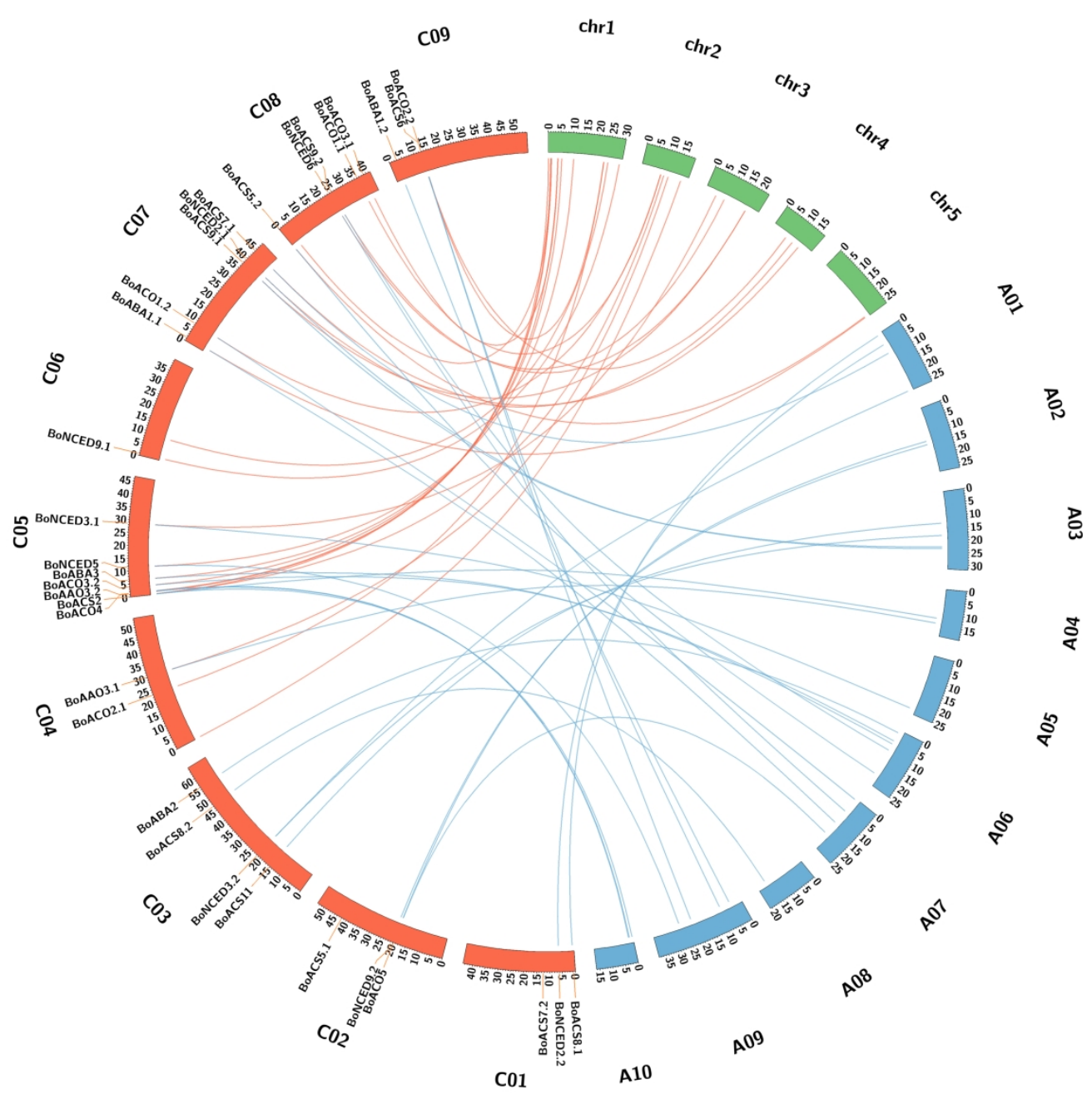

Fig. 4. Microsynteny analysis of abscisic acid (ABA)- and ethylene (ET)-biosynthesis-related genes among $B$. oleracea, B. rapa and A. thaliana. The orange, green and blue colors denote B. oleracea, B. rapa and A. thaliana chromosomes, respectively. 


\begin{tabular}{|l|l|l|l|l|}
\hline TranAcc & GeneName & Description & Purple & Green \\
\hline Bol027222 & BoABA1.1 & Zeaxanthin epoxidase & & \\
\hline Bol019241 & BoABA1.2 & Zeaxanthin epoxidase & & \\
\hline Bol037062 & BoNCED2.1 & 9-cis-epoxycarotenoid dioxygenase NCED2 & & \\
\hline Bol009433 & BoNCED2.2 & 9-cis-epoxycarotenoid dioxygenase NCED2 & & \\
\hline Bol005093 & BoNCED3.1 & 9-cis-epoxycarotenoid dioxygenase NCED3 & & \\
\hline Bol035582 & BoNCED3.2 & 9-cis-epoxycarotenoid dioxygenase NCED3 & & \\
\hline Bol022516 & BoNCED5 & Probable 9-cis-epoxycarotenoid dioxygenase NCED5 & & \\
\hline Bol007451 & BoNCED6 & 9-cis-epoxycarotenoid dioxygenase NCED6 & & \\
\hline Bol027485 & BoNCED9.1 & 9-cis-epoxycarotenoid dioxygenase NCED9 & & \\
\hline Bol018961 & BoNCED9.2 & 9-cis-epoxycarotenoid dioxygenase NCED9 & & \\
\hline Bol035060 & BoABA2 & Xanthoxin dehydrogenase & & \\
\hline Bol026459 & BoAAO3.1 & Abscisic-aldehyde oxidase & & \\
\hline Bol040907 & BoAAO3.2 & Benzaldehyde dehydrogenase (NAD(+)) & & \\
\hline Bol038236 & BoABA3 & Molybdenum cofactor sulfurase & & \\
\hline
\end{tabular}

Fig. 5. Heatmap illustration of the expression pattern of abscisic acid (ABA) biosynthetic genes in purple and green ornamental cabbage lines based on the FPKM data obtained through RNA sequencing of purple (inner) and green (outer) leaves of ornamental cabbage. The red and blue boxes designate the highest and the lowest expression values, respectively. 


\begin{tabular}{|l|l|l|l|l|}
\hline TranAcc & GeneName & Description & Purple & Green \\
\hline Bol040692 & BoACS2 & 1-aminocyclopropane-1-carboxylate synthase 2 & & \\
\hline Bol008070 & BoACS5.1 & 1-aminocyclopropane-1-carboxylate synthase 5 & & \\
\hline Bol005726 & BoACS5.2 & 1-aminocyclopropane-1-carboxylate synthase 5 & & \\
\hline Bol006780 & BoACS6 & 1-aminocyclopropane-1-carboxylate synthase 6 & & \\
\hline Bol042277 & BoACS7.1 & 1-aminocyclopropane-1-carboxylate synthase 7 & & \\
\hline Bol039610 & BoACS7.2 & 1-aminocyclopropane-1-carboxylate synthase 7 & & \\
\hline Bol028890 & BoACS8.1 & 1-aminocyclopropane-1-carboxylate synthase 8 & & \\
\hline Bol032729 & BoACS8.2 & 1-aminocyclopropane-1-carboxylate synthase 8 & & \\
\hline Bol016984 & BoACS9.1 & 1-aminocyclopropane-1-carboxylate synthase 9 & & \\
\hline Bol037340 & BoACS9.2 & 1-aminocyclopropane-1-carboxylate synthase 9 & & \\
\hline Bol015102 & BoACS11 & 1-aminocyclopropane-1-carboxylate synthase 11 & & \\
\hline Bol045912 & BoACO1.1 & 1-aminocyclopropane-1-carboxylate oxidase 1 & & \\
\hline Bol022740 & BoACO1.2 & 1-aminocyclopropane-1-carboxylate oxidase 1 & & \\
\hline Bol006636 & BoACO2.1 & 1-aminocyclopropane-1-carboxylate oxidase & & \\
\hline Bol011006 & BoACO2.2 & 1-aminocyclopropane-1-carboxylate oxidase & & \\
\hline Bol031342 & BoACO3.1 & 1-aminocyclopropane-1-carboxylate oxidase 3 & & \\
\hline Bol010411 & BoACO3.2 & 1-aminocyclopropane-1-carboxylate oxidase 3 & & \\
\hline Bol040946 & BoACO4 & 1-aminocyclopropane-1-carboxylate oxidase 4 & & \\
\hline Bol019026 & BoACO5 & 1-aminocyclopropane-1-carboxylate oxidase 5 & & \\
\hline
\end{tabular}

Fig. 6. Heatmap illustration of the expression pattern of ethylene biosynthetic genes in purple and green ornamental cabbage lines based on the FPKM data obtained through RNA sequencing of purple (inner) and green (outer) leaves of ornamental cabbage. The red, blue and white boxes designate the highest values, the lowest values, and no expression, respectively. 

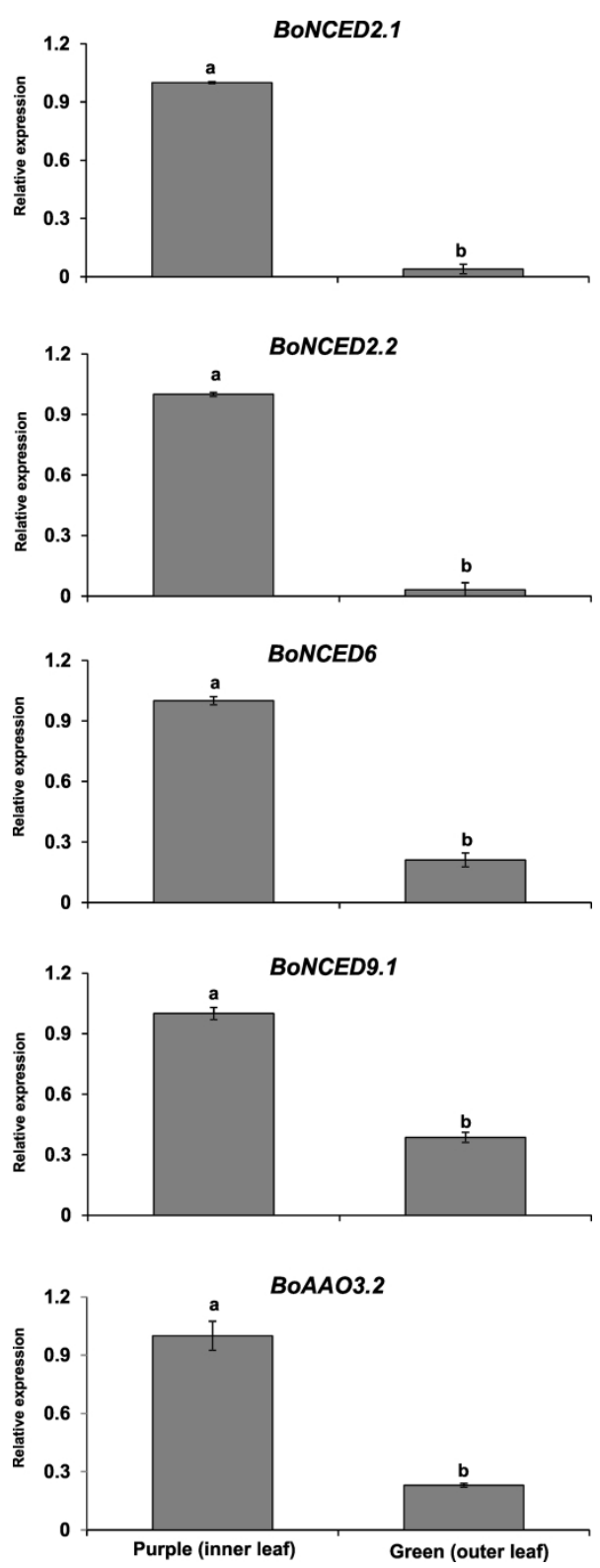

Fig. 7. Expression profiles of abscisic acid (ABA) biosynthetic genes by qRT-PCR in purple (inner) and green (outer) leaves of ornamental cabbage. Error bars represent \pm SE of the means of triplicates. Letters above the bars indicate significant differences.

$136 \times 364 \mathrm{~mm}(300 \times 300 \mathrm{DPI})$ 

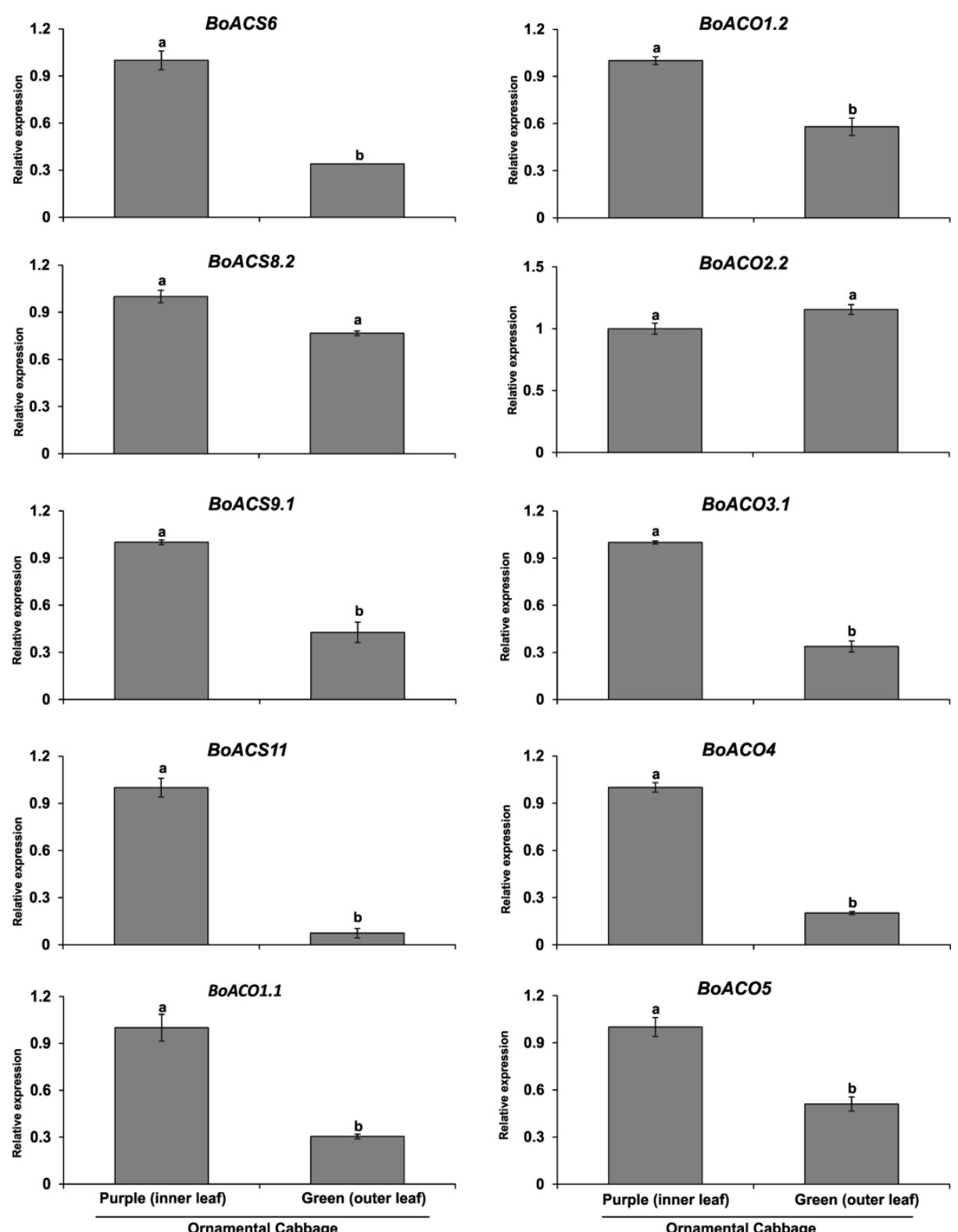

Fig. 8. Expression profiles of ethylene biosynthetic genes by qRT-PCR in purple (inner) and green (outer) leaves of ornamental cabbage. Error bars represent \pm SE of the means of triplicates. Letters above the bars indicate significant differences.

$284 \times 370 \mathrm{~mm}(300 \times 300 \mathrm{DPI})$ 